\title{
La desaprobación del Gobierno mexicano. Más que ineficiencia
}

\section{Mexican government disapproval. Beyond inefficiency}

\author{
doi: http://dx.doi.org/10.32870/ \\ espiral.v25i72.6384
}

\section{Resumen}

Este artículo pone a prueba el argumento de que la ciudadanía de México está inconforme con el Gobierno de su país porque este no ha cumplido sus expectativas, principalmente en lo referente a economía y seguridad, lo que es un problema para la democracia mexicana. Utilizando datos del Latinobarómetro, se encontró que a peor opinión de economía y seguridad, peor evaluación del Gobierno. Sin embargo, dicha relación no apareció cuando se consideraron datos reales de economía y seguridad en lugar de la percepción sobre estas, por lo que se hicieron entrevistas cualitativas en las que se vio que la ciudadanía tiene una expectativa moral de sus funcionarios que parece determinar sus opiniones $y$ estar poco relacionada con el desempeño gubernamental pragmático.

Palabras clave: Gobierno mexicano, desaprobación ciudadana, democracia, economía, seguridad.
Héctor Gutiérrez Sánchez

\begin{abstract}
This paper puts to test the hypothesis that Mexican citizens are dissatisfied with its government because it has not fulfilled expectations, mainly in regard to economy and security, since political discontent with Mexican government has become a problem for democracy in this country. Using data from the Latinobarómetro, it was found that those with worse opinions of economy and security are actually those who held the worse opinion of the government. However, this relationship did not appear when real economic and security data were considered instead of the perception of these, so qualitative interviews were conducted, and it was found that citizens have a moral expectation of their officials that seems to determine their opinions and expectations. This moral demand doesn't appear to be related to pragmatic government performance.
\end{abstract}

Keywords: Mexican government, political disapproval, democracy, economy, security.

-Profesor-Investigador de la Universidad Autónoma de Querétaro, México. ORCID: http:// orcid.org/0000-0002-I387-655X ciudadanohector@yahoo.com.mx

Fecha de recepción: 12 de diciembre de 2016. Fecha de aceptación: 09 de febrero de 2018. 


\section{Introducción}

Este trabajo analiza las causas del desencanto político en México, más específicamente de la desaprobación que los mexicanos muestran hacia sus instituciones y actores políticos.

Repetidamente, se ha mostrado cómo los ciudadanos mexicanos no están contentos con su Gobierno y su clase política, y cuando se intenta explicar este malestar, se suele argumentar que el Gobierno no es eficaz, lo que dificulta la situación económica y de seguridad. Sin embargo, los datos empíricos sólo confirman esa hipótesis limitadamente, pues sí parece haber una relación entre la evaluación del Gobierno y la percepción subjetiva de economía y seguridad, pero dicha relación desaparece cuando se sustituye la percepción de ambos temas por datos objetivos sobre ellos.

El desempeño del Gobierno no parece, entonces, ser la única causa de su desaprobación, por lo que este estudio documenta la realización de una serie de entrevistas cualitativas cuyo objetivo fue comprender cómo los ciudadanos juzgan a sus Gobiernos y gobernantes. Las entrevistas revelaron que los ciudadanos esperan mucho más que sólo funcionarios eficientes, pues desean ver en ellos a figuras morales y líderes que sean ejemplos de civismo. El incumplimiento de estas demandas morales parece determinar mucho del descontento ciudadano hacia los políticos e instituciones, al menos respecto al desempeño de los funcionarios. Este hallazgo dialoga con ideas muy arraigadas en la ciencia política, pues la secularización del Estado suele reducir a los gobernantes a meros tomadores de decisiones desprovistos de toda sacralidad, cuando lo aquí encontrado parece recuperar ideas de otras disciplinas como la sociología, historia y antropología, que describen un ejercicio del poder político lleno de connotaciones morales y simbólicas.

\section{4}


Primero, se hace una breve introducción histórica del desencanto con los Gobiernos y gobernantes, pues este asunto no siempre fue tan preocupante ni tuvo las mismas repercusiones para la sociedad mexicana como ahora. Luego, se recupera el argumento según el cual la desaprobación ciudadana se debe a la incompetencia de los Gobiernos, idea que es luego puesta a prueba. El resultado justifica la necesidad de indagar más el tema, lo que da pie al trabajo cualitativo. Entonces, tras describir la metodología utilizada, se presentan los resultados. En ellos, se pone particular atención al elemento moral que parece determinar mucho del juicio de los ciudadanos. Finalmente, los hallazgos son recuperados para presentar reflexiones finales.

\section{El desencanto político y sus causas}

Tanto trabajos plenamente académicos como medios de comunicación masiva advierten constantemente que la ciudadanía mexicana está descontenta con sus políticos y su Gobierno. Ante esto, pareciera simplista y obvio pensar que el Gobierno es malo y que por eso se le juzga así, sin embargo, la opinión pública es un fenómeno complejo que ni siquiera tiene siempre las mismas implicaciones. Para empezar, el desencanto político tiene distintos roles y causas según el grado de consolidación de la democracia (Torcal, 2003), además, importantes cambios en la historia mexicana reciente han modificado el papel del desencanto ciudadano.

Por muchos años, México tuvo un partido hegemónico, el Revolucionario Institucional (PRI), en cuyo interior sucedían las negociaciones y acuerdos que determinaban la vida política nacional. En aquel contexto, "las elecciones se convertían en un ritual de ratificación de un poder previamente asignado" (Gómez, 2009, p. 97), por lo que la voz y el sentir ciudadano no tenían tanta relevancia. 
A partir de 1980, el partido hegemónico comenzó a sufrir reveces electorales e inició un proceso de democratización en México. Durante este periodo, la desaprobación y el desencanto con los políticos parecían ser el motor que impulsaba la búsqueda de democracia en el país. En aquellos años, proliferaron los estudios sobre cultura política (Assies, Calderón y Salman, 2002; Alonso, 1994; Krotz, 1990 y 1996; Zemelman, 1990), varios de los cuales sugerían que la ideología del mexicano se hacía cada vez más democrática, lo que generaba cada vez más descontento con las prácticas y estructuras del partido hegemónico. En los años previos a la transición democrática, el malestar con el Gobierno y sus actores parecía ser una fuerza útil, pues se canalizaba a propuestas democratizadoras.

Después del año 2000, la desaprobación ciudadana tomó un matiz desesperanzador al convertirse en un malestar sin destino, proyecto ni utilidad aparente. Mora y Rodríguez (2003) realizaron uno de los primeros trabajos sobre el tema después del triunfo electoral de Vicente Fox (presidente de México entre 2000 y 2006). Su estudio mostraba una ciudadanía insatisfecha con la democracia que había construido, pero sin nuevas propuestas, y hacía énfasis en la caída de la popularidad presidencial y cómo esta coincidió con una baja en la participación electoral en 2003. Ya desde ese temprano trabajo se culpaba al desempeño del Gobierno:

En el sentir del ciudadano común, la algarabía transicionista con su nuevo Gobierno resultaba frustrante, luego de no percibirse acciones contundentes orientadas tanto a ordenar el caos político como a mejorar la calidad de vida, que era por lo que finalmente se había votado (Mora y Rodríguez, 2003, p. 56).

Este nuevo descontento mexicano ha sido analizado por académicos, quienes lo ven como causa de abstencionismo electoral. El estudio de Mora y Rodríguez ya contenía esta idea, 
misma que prosperó en muchos artículos posteriores (Lutz, 2005a y 2005b; Alonso, 2010; Mijares, 2006; Gutiérrez, 2017).

El mismo fenómeno se ha visto en otros países (Valencia, Pelaéz, Rúa y Awad, 2010), aunque no sin contraejemplos internacionales (Miller, 1980). El desencanto político también ha sido vinculado con otras desviaciones de la participación electoral, como el voto nulo (Lutz, 2005a; Alonso, 2010).

Nótese cómo el descontento que otrora favoreció la democracia ahora corroe su cimiento electoral; el nuevo desencanto no parece ser una fuerza productiva, sino un problema. Este sentir ciudadano también parece vincularse con retrocesos autoritarios, pues es condición necesaria para el surgimiento de ciertas figuras carismáticas que frecuentemente recurren a la violencia, limitan libertades y vulneran la democracia: hoy día, los académicos ven con preocupación la situación política y social de Venezuela y la llegada de Donald Trump a la presidencia estadounidense, ambos fenómenos difíciles de entender sin un antecedente de estudio sobre el desencanto político.

El juicio que los ciudadanos hacen del Gobierno parece amenazar a la joven democracia mexicana. Esta podría ser su consecuencia más dramática, pero dista de ser la única. La opinión popular también tiene importantes repercusiones coyunturales, por ejemplo, la calificación de un Gobierno, partido o figura pública puede ser usada por sus adversarios políticos para obtener ventajas. Este tipo de motivaciones vuelve relevante el tema de la medición del pulso ciudadano, de ahí que se discuta el rol de las encuestas, así como su posible divulgación en la ciudadanía y su uso estratégico (Hurtado, 2014; Sánchez y Aceves, 2008).

La opinión pública es relevante a la luz de coyunturas, por lo que su medición y uso para estudios ha sido debatido, sin embargo, el presente trabajo se concentra en la desaprobación general del Gobierno, misma que conforme se volvió un problema llamó la atención de investigadores que han 
tratado de saber qué la determina. Algunos pocos proponen que la ciudadanía se está desinteresando de todo lo público (López Sánchez, 2013), pero generalmente se piensa que sí hay interés ciudadano, sólo que este no se ve reflejado en la oferta política.

Los principales esfuerzos por explicar el desencanto se encuentran en las investigaciones sobre apoyo a la democracia (Schedler y Sarsfield, 2009; Sarsfield, 2004; Zovatto, 2002; Magallón, 1993; Córdova y Seligson, 2010; Cuna, 2006 y 2012; Meixueiro, 2009). Algunos de estos trabajos investigan más de un país, pero suelen coincidir en que los mexicanos son demócratas insatisfechos. Esto significa que el pueblo de México sí apoya a la democracia como un ideal, pero se siente insatisfecho con los resultados de su Gobierno en concreto. Esta aparente contradicción se suele explicar señalando que muchos ciudadanos no creen vivir en una democracia verdadera, lo que les permite apoyar la democracia pero desaprobar a su Gobierno.

Dejando de lado el apoyo a la democracia como ideal, la mayoría de los estudios coinciden en señalar que la incompetencia y pobres resultados de los Gobiernos causan el descontento con estos: "El Estado y sus instituciones requieren[,] pues[,] de la legitimidad que les aportan los individuos[,] y al Gobierno, los ciudadanos. Esta legitimidad se fundamenta por el desempeño gubernamental para alcanzar los objetivos de Estado propuestos (aquí la clave es la eficacia)" (García, 2004, p. 175). Por tanto, se señala que "tienen culpa los políticos y las instituciones, que agravaron las dificultades con su pobre desempeño" (Cuna, 2006, p. 99), y que, además,

Ese desencanto se expresa tanto por una sensación de ineficacia del sistema político actual en cuanto a sus resultados generales y mecanismos de toma de decisiones, así como por una decepción en cuanto al ritmo 
de integración de derechos asociados a valores democráticos en la vida pública nacional (cambio de prácticas políticas) (Prud’homme, 20I5, p. 328).

Cuando se profundiza sobre lo que implica el desempeño o la eficacia, usualmente se habla de resultados en economía y seguridad: "Esta evaluación se explica por la expectativa de los ciudadanos en tres elementos de su vida práctica: cómo la política ayuda en el combate a la pobreza, a la generación de empleo y al mantenimiento de la seguridad pública" (Cuna, 2012, p. 115); "la insatisfacción con los resultados económicos y sociales tiende a dirigirse contra el sistema político" (Cuna, 2012, p. 113).

Esto coincide perfectamente con las ideas de Arend (1999), quien también propone a la economía y la seguridad (manejo de la violencia) como los dos elementos principales para evaluar el desempeño de un Gobierno.

Para el caso mexicano, los investigadores frecuentemente apuntan al desempeño del Gobierno como causa de su desaprobación. También se suele mencionar la corrupción como otro factor, pero con menos frecuencia y énfasis. En otros países, en cambio, se encuentran un mayor número de posibles explicaciones, por ejemplo, hay trabajos que revisan si los medios de comunicación (al concentrarse en malas noticias) se relacionan con la evaluación del Gobierno y sus funcionarios (Street, 2011; Pinkleton, Austin, Zhou, Willoughby y Reiser, 2012; Schmitt-Beck y Mackenrodt, 2010). Esta idea sólo generó un tímido eco en México (Molina y Vedia, 2004).

A nivel internacional, se ha discutido también la confianza social como un determinante de la participación y del desencanto político (Schyns y Koop, 2010; Sun, Hu y Wu, 2012; Gil de Zúñiga, Jung y Valenzuela, 2012). Estos estudios tienen atractivo, pero dado que analizan contextos tan diferentes, son de poca utilidad para entender al ciuda- 
dano mexicano, pues como se mencionó antes, el contexto importa mucho al analizar la opinión pública.

Como se dijo antes, para el caso mexicano, la literatura parece sugerir que el desempeño del Gobierno en temas de seguridad y economía es la principal causa del descontento ciudadano, conclusión que puede parecer lógica, casi obvia, pero los datos no apoyan del todo esta hipótesis. Investigar este asunto no es demasiado complejo en la medida en que ya existen varias encuestas políticas y se encuentran disponibles las bases de datos de la Encuesta Nacional de Cultura Política (ENCUP), del informe país sobre la calidad de la ciudadanía en México, del Barómetro de las Américas y del Latinobarómetro; finalmente, el proyecto Los mexicanos vistos por sí mismos incluye una encuesta sobre política cuya base también es de acceso público.

Para investigar la relación de la opinión ciudadana con el desempeño gubernamental, se decidió en el presente estudio usar los datos sobre México del Latinobarómetro, pues esta encuesta es la que más se acerca a un trabajo longitudinal, ya que se ha repetido con más regularidad y por un periodo más largo que cualquiera otra. Esto será útil más adelante al introducir el factor tiempo. Adicionalmente, el Latinobarómetro es una de las encuestas más populares en los estudios sobre apoyo a la democracia, por lo que su uso homogeniza los procedimientos y hallazgos.

Los resultados aquí mostrados utilizan sólo datos de México, las preguntas sobre cuánto se confía en el Congreso, en el Gobierno, en los partidos y en el Estado, así como la evaluación del trabajo de Congreso y partidos. Para determinar la percepción de economía y seguridad, se recuperaron los reactivos sobre el funcionamiento general de la economía, situación económica del país y evaluación de seguridad. Los datos del Latinobarómetro a nivel persona muestran un fuerte descontento ciudadano, así como una relación entre la evaluación del Gobierno y la percepción 
de economía y seguridad. Para saber esto, se utilizaron pruebas $\mathrm{X}^{2}$ de tabla de contingencia con las variables antes mencionadas.

Evalúan mejor al Gobierno quienes tienen mejores impresiones de la economía y seguridad, lo que pareciera confirmar al desempeño del Estado como causa del desencanto. Sin embargo, no se busca saber si la mala imagen del Gobierno se debe a su eficacia percibida, sino su desempeño real, lo que implica trabajar con mediciones objetivas de los logros objetivos del Gobierno. Para hacer esto, se cambió el nivel de medición y se hicieron análisis a nivel agregado, ya sea en tiempo o en espacio.

Las variables antes revisadas fueron analizadas a nivel estado. Se hizo un promedio de las respuestas de todos los informantes de cada entidad federativa y estas se vaciaron en una base nueva con sólo treinta y dos casos, misma que se comportó de forma semejante al análisis antes descrito: así como los informantes con mejores percepciones de economía y seguridad evaluaban mejor al Gobierno, también los estados del país con mejores opiniones sobre economía y seguridad son los que menos descontento muestran. Trabajar a nivel agregado implicó subir el nivel de medición, es decir, ya no se utilizaron frecuencias de un reactivo tipo Likert, sino promedios, por lo que se dejaron las pruebas $\mathrm{X}^{2} \mathrm{y}$ se hicieron análisis de correlaciones y regresiones (Tabla 1).

Cada celda de la Tabla 1 contiene el coeficiente correlación de Pearsons ${ }^{1}$ entre las variables de su fila y columna. Se incluye también el valor P de una regresión simple de mínimos cuadrados ordinarios con esas mismas dos variables. ${ }^{2}$ Tal y como sucedió con las pruebas de $\mathrm{X}^{2}$ a nivel persona,

I. Cabe recordar que el coeficiente de correlación de Pearsons toma un valor de cero cuando no hay ninguna relación lineal, y no puede ser mayor a uno.

2. Cuando el valor $P$ es menor a .05 , se considera que hay evidencia de relación estadística entre variables con una certeza del $95 \%$. A menor valor $\mathrm{P}$, más certeza hay de la relación. 
la Tabla 1 muestra una clara relación entre opiniones de economía-seguridad y la evaluación del Gobierno, sólo que esta vez a nivel estado.

Tabla 1. Correlaciones entre evaluación del Gobierno y opiniones subjetivas de economía y seguridad a nivel estado

\begin{tabular}{ccccc} 
& $\begin{array}{c}\text { Funcionamiento } \\
\text { general de la } \\
\text { economía }\end{array}$ & $\begin{array}{c}\text { Situación } \\
\text { económica } \\
\text { del país }\end{array}$ & $\begin{array}{c}\text { Evaluación } \\
\text { seguridad }\end{array}$ & $\begin{array}{c}\text { Situación } \\
\text { económica } \\
\text { personal }\end{array}$ \\
$\begin{array}{c}\text { Confianza } \\
\text { en Congreso } \\
\text { Confianza } \\
\text { en Gobierno } \\
\text { Confianza }\end{array}$ & $.5863 / .000$ & $.7520 / .000$ & $.5301 / .002$ & $.0559 / .761$ \\
$\begin{array}{c}\text { en partidos } \\
\text { Confianza } \\
\text { en Estado }\end{array}$ & $.3622 / .042$ & $.7205 / .000$ & $.5559 / .001$ & $.2986 / .097$ \\
$\begin{array}{c}\text { Evaluación } \\
\text { trabajo }\end{array}$ & $.4633 / .041$ & $.5595 / .001$ & $.5873 / .000$ & $.4732 / .006$ \\
$\begin{array}{c}\text { Congreso } \\
\text { Evaluación } \\
\text { trabajo } \\
\text { partidos }\end{array}$ & $.3289 / .023$ & $.7145 / .000$ & $.5517 / .001$ & $.4029 / .022$ \\
\hline
\end{tabular}

Fuente: elaboración propia con datos de Latinobarómetro (2015).

Tanto la variable sobre la situación económica como la de seguridad muestran correlaciones mayores a .5, y todas son significativas con un P menor a .05, esto pese a tener sólo treinta y dos casos. Por alguna razón, la pregunta sobre la situación general de la economía presenta relaciones menos claras con la evaluación del Gobierno, aunque la mayoría de sus correlaciones son significativas con una confianza del 95\%. Se ha incluido también una columna sobre situación personal, misma que será recuperada más adelante.

Es decir, a nivel persona y a nivel estado, las opiniones sobre economía y seguridad se vinculan con la evaluación 
del Gobierno, pero si el desempeño del Gobierno causara su mala evaluación, se esperaría que los indicadores objetivos de economía y seguridad también estuvieran relacionados con el descontento ciudadano. Para revisar esto, se sustituyeron las opiniones subjetivas que recoge el Latinobarómetro por datos objetivos sobre seguridad y economía. ${ }^{3}$

La Tabla 2 contiene correlaciones de las mismas variables sobre evaluación del Gobierno a nivel estado, pero no relacionadas con la percepción sobre economía y seguridad, sino con datos reales de economía y seguridad. Los datos económicos incluyeron el producto interno bruto (PIB) per cápita por ser el indicador más obvio de riqueza, pero la distribución del ingreso en México es muy desigual, por lo que se incluyó el porcentaje de pobreza y el desempleo, indicadores que podrían ser más sensibles para la población general.

Por otro lado, se utilizó la prevalencia delictiva como indicador de seguridad. Se eligió este indicador por su amplio espectro, lo que debería de hacerlo más significativo que otras variables sobre delitos con mayor impacto pero menor frecuencia. Se aproximaron lo más que fue posible la fecha del levantamiento de los datos objetivos y el momento en que se realizó la encuesta del Latinobarómetro.

Las diferencias entre las Tablas 1 y 2 son evidentes: el $77 \%$ de las correlaciones en la Tabla 1 (excluyendo situación económica individual) es mayor a .4, mientras que ninguna correlación de la Tabla 2 alcanza dicho valor; el 72\% de las relaciones de la Tabla 1 son significativas con más del 99\% de confianza, mientras que ninguna relación de la Tabla 2 es significativa con esa misma confianza.

3. Se agradece el apoyo de la licenciada Betsy Elizabeth Torroella Olvera en la recopilación de datos y elaboración de bases. 
Tabla 2. Correlaciones entre evaluación del Gobierno y datos objetivos de economía y seguridad a nivel estado

\begin{tabular}{|c|c|c|c|c|}
\hline & $\begin{array}{l}\text { Porcentaje de } \\
\text { pobreza } 2014\end{array}$ & $\begin{array}{c}\text { PIB per } \\
\text { cápita } 2014\end{array}$ & $\begin{array}{c}\text { Desempleo } \\
\text { noviembre } \\
2015\end{array}$ & $\begin{array}{c}\text { Prevalencia } \\
\text { delictiva } \\
2015\end{array}$ \\
\hline $\begin{array}{c}\text { Confianza } \\
\text { en Congreso }\end{array}$ & $-.2784 / .123$ & $.3784 / .033$ & $.1469 / .422$ & $.3681 / .038$ \\
\hline $\begin{array}{c}\text { Confianza } \\
\text { Gobierno }\end{array}$ & $-.1962 / .282$ & $.2139 / .240$ & $.2388 / .188$ & $.3897 / .027$ \\
\hline $\begin{array}{c}\text { Confianza } \\
\text { en partidos }\end{array}$ & $.1629 / .373$ & $.1605 / .380$ & $.1658 / .364$ & $.1978 / .278$ \\
\hline $\begin{array}{l}\text { Confianza } \\
\text { en Estado }\end{array}$ & $.0522 / .777$ & $.0046 / .980$ & $-.0337 / .855$ & $.0224 / .903$ \\
\hline $\begin{array}{c}\text { Evaluación } \\
\text { trabajo } \\
\text { Congreso }\end{array}$ & $-.1498 / .413$ & $.2491 / .169$ & $.0466 / .800$ & $.2526 / .1163$ \\
\hline $\begin{array}{c}\text { Evaluación } \\
\text { trabajo } \\
\text { partidos }\end{array}$ & $-.1004 / .584$ & $.2018 / .268$ & $.1746 / .339$ & $.2825 / .117$ \\
\hline
\end{tabular}

Fuente: elaboración propia con datos del Latinobarómetro (2015), Instituto Nacional de Estadística y Geografía (2016), Banco Mundial (2017) y Consejo Nacional de Evaluación de la Política de Desarrollo Social (2015a).

Con los mismos treinta y dos casos, la Tabla 1 contiene relaciones muy claras con valores P menores a .001, mientras que la Tabla 2 sólo contiene valores P de .027 o superiores. Además, la Tabla 2 contiene veinticuatro pruebas de hipótesis, lo que aumenta la probabilidad de error tipo 2, así que algunas de las relaciones apenas significativas podrían de hecho ser falsos positivos. Los datos muestran que la evaluación del Gobierno sí se relaciona con la percepción sobre temas de seguridad y economía, pero no con resultados reales sobre economía y seguridad. Esta conclusión se puede afianzar aún más.

La Tabla 1 incluye una columna especial en su extremo derecho que habla de la situación económica del informante en particular (no del país en general). Dicha columna sí 
mostró relaciones claramente significativas con la evaluación del Gobierno, pero fueron menores comparadas con las de otras columnas. Esto podría sugerir que los ciudadanos no evalúan al Gobierno en función de su condición individual o la de su estado, sino por la situación de todo el país, lo que complicaría la interpretación de las estadísticas antes presentadas. Por ejemplo, un mexicano rico podría estar descontento con la economía nacional porque, a pesar de su condición personal, percibe mucha pobreza en el país, lo que dificultaría encontrar la relación economía real-descontento.

Para enfrentar esto, nuevamente se trabajó a nivel agregado, pero en tiempo, ya no en espacio. El Latinobarómetro no ha cambiado por varios años sus preguntas sobre confianza en instituciones, por lo que se puede hacer una serie histórica y analizar si los años con mejor desempeño gubernamental se caracterizan por una mejora en la evaluación ciudadana (Figura 1).

La Figura 1 contiene gráficas con diversos valores nacionales a través del tiempo. Sólo se recuperaron datos a partir del año 2000 por ser este un año de cambios políticos en México y porque es difícil conseguir series de tiempo muy largas. Los datos de desconfianza en instituciones provienen del Latinobarómetro, mientras que los de economía y seguridad son del Instituto Nacional de Estadística y Geografía (INEGI) y del Consejo Nacional de Evaluación de la Política de Desarrollo Social (CONEVAL). Algunos indicadores como el porcentaje de pobreza alimentaria fueron escalados para que su inclusión en la Figura 1 no alterara su dimensión y dificultara su legibilidad.

El primer cuadro (superior izquierdo) de la Figura 1 muestra únicamente datos del Latinobarómetro y contiene la desconfianza en Congreso, partidos y Gobierno. Dicho valor sólo va de 1 a 4 y muestra cómo la desconfianza en estas instituciones es muy alta y muy estable; únicamente se logra apreciar cierto aumento alrededor del 2003, quizá 
debido a que la transición democrática no fue tan provechosa como la población anhelaba.

Figura 1. Histórico de la evaluación del Gobierno y datos objetivos de economía y seguridad a nivel país
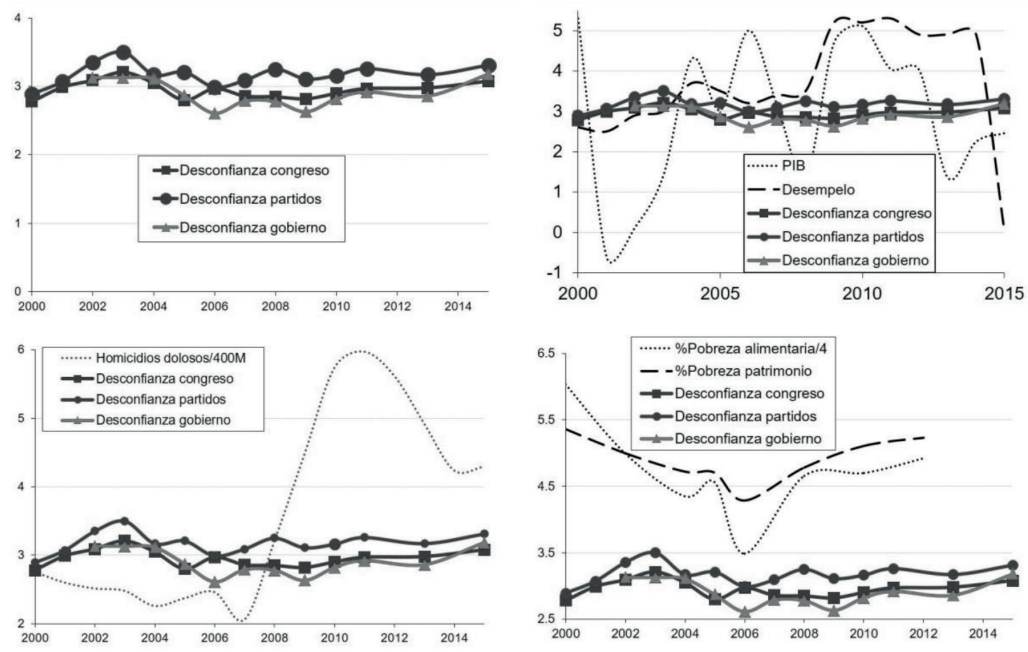

Fuente: elaboración propia con datos del Latinobarómetro (2015), Instituto Nacional de Estadística y Geografía (2016), Banco Mundial (2017) y Consejo Nacional de Evaluación de la Política de Desarrollo Social (2015b).

Contrario a la desconfianza política, los indicadores sobre economía y seguridad muestran fuertes variaciones a lo largo del tiempo. La gráfica superior derecha de la Figura 1 recupera las series sobre desconfianza y agrega la evolución de los homicidios dolosos. Se puede apreciar un violento repunte en los años de inicio de la guerra contra el narcotráfico, llevada a cabo durante el periodo presidencial de Felipe Calderón (2006-2012), así como cierta estabilización hacia el final de la serie, pero ninguno de estos cambios parece afectar los indicadores de desconfianza.

Algo semejante sucede con la gráfica inferior izquierda de la misma Figura 1, que incluye datos sobre pobreza. Dicha 
gráfica pareciera tener un descenso hacia 2006, pero este tampoco parece vincularse con cambios en la desconfianza. De hecho, la pobreza parece estar a la baja en el inicio de la serie, mientras la desconfianza subía.

La última gráfica de la Figura 1 repite el patrón, pues muestra cómo los cambios en el crecimiento del PIB nacional y en el desempleo cambian mucho, pero no parecen incidir en la impasible desconfianza ciudadana.

Se suele pensar que el Gobierno es mal evaluado por su mal desempeño, y ciertamente quienes tienen opiniones negativas de la situación económica y la seguridad evalúan peor al Gobierno. Sin embargo, no hay una relación clara entre el desempeño real del Gobierno y su evaluación. Como se usaron datos agregados, podría temerse una falacia ecológica, pero el desempeño gubernamental subjetivo a nivel estado sí se relacionó con la evaluación del Gobierno a ese mismo nivel, lo que no sucedió al analizar indicadores objetivos.

Podría también pensarse que la evaluación del Gobierno depende del estado general de la nación y no de la situación personal del informante, pero tampoco parece haber relación entre la evolución nacional histórica de la seguridadeconomía y la evaluación del Gobierno.

Además, la ciudadanía parece poco capaz de evaluar la economía y la seguridad, lo que es condición necesaria si su juicio sobre el Gobierno depende del desempeño objetivo de este: usando regresiones simples y un a de .05, se encontró que la variable sobre situación económica personal no se relaciona a nivel estado con el desempleo ni con el PIB per cápita ni con el porcentaje de personas en situación de pobreza de las entidades federativas. Con la misma técnica, se halló que la evaluación subjetiva de seguridad tampoco se relaciona con la prevalencia delictiva. Todo esto significa que los estados más ricos no son los que tienen más informantes que se dicen prósperos, y que los más seguros no tienen encuestados con mejores evaluaciones de seguridad. 
Esto deja claro que el desempeño del Gobierno no es causa obvia ni única de la evaluación de este: hay una relación (no necesariamente causal) entre la percepción subjetiva del desempeño del Estado y su valoración, pero no parece haberla entre el desempeño real de este y su evaluación. En el contexto actual, la desaprobación ciudadana es un importante problema para la democracia mexicana, y si no está directamente relacionada con el desempeño del Gobierno como se pensaba, es imperativo conocer qué la determina.

\section{La demanda moral insatisfecha}

Como señala Claus Offe (2006), las encuestas logran medir actitudes y opiniones, pero regularmente muestran poco sobre cómo se llega a dichas opiniones. El desencanto mexicano pareciera estar en una situación semejante. Así, trabajos como el Informe pais, el Latinobarómetro y la ENCUP muestran claramente un descontento ciudadano, pero no dicen demasiado respecto a cómo se generan esas opiniones.

Metodológicamente es posible poner a prueba una hipótesis causal a través de una encuesta, lo que generalmente se hace midiendo una variable independiente (causa) y una dependiente (efecto) para después buscar algún tipo de covariación. Este procedimiento bien puede favorecer la hipótesis causal bajo escrutinio, pero se vuelve estéril cuando la refuta, pues nada garantiza la emergencia de una nueva hipótesis causal cuando la anterior es rechazada.

La clave aquí es que el método cuantitativo es más bien deductivo, lo que fue perfecto en el primer momento de este estudio, cuando se tenía una hipótesis clara sobre qué causa la evaluación ciudadana, pero la herramienta cuantitativa parece contradecir la hipótesis planteada, y al hacer esto llega a su límite, pues esa refutación puede evitarnos errores, pero no aporta una nueva explicación, es más, peor aún, al analizarse datos de encuestas ya realizadas, no hay

\section{8}


siquiera garantía de que las nuevas variables explicativas se encuentren suficientemente medidas en estas bases. Generar nuevas hipótesis que nos lleven a explicar la evaluación ciudadana requiere un cambio metodológico hacia herramientas más inductivas.

Esta necesidad sugirió el uso de métodos cualitativos, con los cuales es posible generar nuevas hipótesis que podrían explicar mejor lo que el desempeño gubernamental objetivo parece no determinar. Además, la tradición cualitativa está muy enfocada en la comprensión y en la subjetividad, lo que es muy conveniente para el momento del estudio en que se intenta descifrar una percepción ciudadana, esto es, si el desempeño del Estado no parece determinar mucho del juicio que la gente hace, ¿qué sí explica dicha opinión?

Para comenzar a responder esta pregunta, se realizaron entrevistas focalizadas o centradas (Merton y Kendall, 1946). Este tipo de entrevistas están a medio camino entre las propiamente estructuradas (con preguntas fijas) y las no estructuradas, en las que se deja al informante en casi total libertad. A cada entrevistado se le dio un tema específico, y para comprender mejor su punto de vista se le dejó explayarse al respecto, pero cuando algún elemento parecía trascendente, se profundizaba en él.

Pocas investigaciones utilizan metodología cualitativa para analizar desencanto político o apoyo a la democracia. Una excepción es el trabajo de Cuna (2006), aunque en él se entrevistaron sólo a jóvenes universitarios. Las entrevistas realizadas para este estudio fueron a población general; contrario al trabajo de Cuna (2006), ningún informante era politólogo, y no se forzó ninguna pregunta. Estas precauciones mejoraron la representatividad de los datos, aumentando así su valor.

En total se hicieron treinta entrevistas. Trece de ellas fueron grabadas y sirvieron para extraer los fragmentos que más adelante serán usados para ejemplificar hallazgos. La 
tasa de rechazo fue baja (menos de cinco rechazos). Algunas entrevistas eran inicialmente rechazadas porque los informantes decían tener hartazgo y rechazo a la política, pero cuando se preguntaban las razones de dicho rechazo, se lograba una charla productiva. Todo esto reduce la posibilidad de un sesgo de autoselección. Seis entrevistas se realizaron en Ciudad Universitaria a estudiantes de la Benemérita Universidad Autónoma de Puebla; las demás se hicieron en el primer cuadro de la ciudad de Puebla a personas que parecían dispuestas a charlar por unos minutos, sin distinción de su edad o apariencia.

Estas entrevistas se realizaron entre el 27 y el 29 de junio de 2016, a unos días de las elecciones en Puebla. El trabajo de campo se hizo poco antes de dicha votación porque aunque la opinión pública importa en todo momento, cuando se recoge en las urnas es cuando más relevancia política tiene.

Por otro lado, la elección de Puebla tuvo muchas ventajas: en primer lugar, los dos principales candidatos que buscaban el cargo de gobernador habían sido ya presidentes municipales, así que fue posible conocer el grado en que los resultados concretos de una administración afectan el juicio de los entrevistados; en segundo lugar, las figuras ejecutivas (más que las instituciones) paren ser muy relevantes en el juicio ciudadano (Gutiérrez, 2017), y Puebla tuvo elección de gobernador en 2016; en tercer lugar, en el mismo año sólo trece estados del país tuvieron elecciones, y Puebla fue la ciudad más grande entre las de dichos estados con comicios regulares, ${ }^{4}$ además de que su posición como la cuarta mayor ciudad del país agrega representatividad a los datos ahí

4. La Ciudad de México tuvo elecciones en 2016, pero se realizaron en el marco de un proceso extraordinario para elegir una asamblea constituyente, esto como parte del proceso para hacer del hasta entonces Distrito Federal un estado más de la federación. 
obtenidos, pues no se trata de una localidad muy pequeña ni de una gran ciudad.

Finalmente, el contexto político fue conveniente. La elección en Puebla no estuvo marcada por fuertes escándalos del gobernador saliente (como en Veracruz) ni estuvo enrarecida por la presencia de grupos armados (como en Tamaulipas). De hecho, el candidato ganador fue del mismo partido que el gobernador saliente, y siempre se mostró cercano a él. La elección poblana fue una especie de ratificación del partido que se encontraba en el Gobierno, lo que permitió ver claramente cómo la ciudadanía juzga a sus gobernantes.

Las respuestas de los entrevistados dejaron claro el descontento con los políticos, candidatos y el Gobierno en general: ${ }^{5}$
¿Te gustan los candidatos?
-No, los candidatos no.
-Todos son falsos, todos mentirosos, prometen y prometen y ya que están en la silla se llevan todo el dinero de los ciudadanos.
-Pues pienso que todos son corruptos.
- Todos son lo mismo, todos entran diciendo que no van a robar y ya cuando les falta[n] uno [o] dos años, buscan el modo de llevarse lo que pueden, entonces créame que desde que yo tengo uso de razón, todos son iguales.

Este descontento evidenciado en las respuestas es un asunto ya bien conocido. Se buscó profundizar sobre cómo los entrevistados llegan a esas opiniones negativas, y rápidamente se notó que el desempeño gubernamental sí era reconocido entre ellos como un tema significativo, pero había algo más,

5. Se incluyen la pregunta en letras itálicas (cursivas) y las respuestas seleccionadas en tipografía redonda. Cada guion corto (-) indica la respuesta o fragmento de respuesta de un entrevistado distinto. Las grabaciones completas de las entrevistas realizadas están en poder del autor del artículo. 
un elemento que los informantes describían con dificultad aun siendo relevante:

¿Cómo decides un candidato sobre otro, en qué te fijas?

-Básicamente en su trabajo previo.

\section{¿Trabajo previo?}

-Cómo es como persona y cómo es como candidato, qué propone, qué ofrece y cómo lleva su propio proceso de campaña.

En el ejemplo extraído de las entrevistas, el informante no sólo juzga al político "como candidato", lo que probablemente refiere al trabajo previo y a su desempeño en la administración pública, sino que además lo evalúa "como persona". Este elemento de consideración ajeno a la eficacia de los Gobiernos se repitió en otros casos con algunas variaciones:

Ok, entonces, tú lo ves como una especie de administrador financiero.

-Algo así.

¿Qué más debería de ser un gobernador?

-En su persona, tal vez, una persona, realmente, ¿cómo llamarlo?, una persona de respeto, que, con los lineamientos que se esté llevando [sic], personales y dentro del título [sic], realmente los lleve.

Los entrevistados hablan entonces de los candidatos y gobernantes "como personas" y "persona de respeto", y el del ejemplo inmediato anterior incluso muestra dificultades para describir esa idea.

Otros entrevistados dijeron querer funcionarios "más humildes", que "se identifiquen más con la gente", mientras que otros más consideraban importantes "su ánimo, su presencia, [...] su personalidad". Salvo unas pocas excepciones señaladas más adelante, todos los entrevistados tenían expectativas ajenas al desempeño del Gobierno y mostra- 
ban tartamudeos o dificultades significativas al tratar de describir en qué consistían dichas expectativas:

-Bueno, es que yo soy de la idea de que una persona desde los fundamentos que tenga es como se presenta y reacciona hacia, hacia lo que está, o sea, un buen líder, si eres una persona honesta, si eres una persona ya con valores fundamentados, pues vas a actuar de la misma manera.

¿Por qué te preocupa que tengan valores?

-Porque, digámoslo así, es básico, si tú no tienes valores, ¿cómo puedes llevar ciertas cosas?, es decir, si tú no respetas o no tienes ese respeto hacia las personas, ¿cómo esperas que los demás lo tengan?

-En su persona, tal vez, una persona, realmente, ¿cómo llamarlo?, una persona de respeto, que, con los lineamientos que se esté[n] llevando, personales y dentro del título, realmente los lleve, es decir, que lleve una coherencia con lo que hace, con lo que dice, que muestre un respeto ahora sí que por la gente que votó por él.

$Y$ ¿a qué te refieres con persona?

-Saber si no es una, si es una persona que es, este, si es humana, si no es una persona que haya estado involucrada en actos delictivos.

Nótese el uso de la palabra líder, que será recuperada en las conclusiones. Cada fragmento arriba mostrado contiene un número importante de muletillas y frases incompletas en comparación con otras secciones de la misma entrevista. El deseo ciudadano parece entonces intenso, pero muy vago. Las personas esperan que sus gobernantes tengan virtudes aparentemente morales, pero parecen no poder explicar por qué. Intentando indagar más en el tema, se les preguntaba a los entrevistados si esa expectativa moral también aplicaba a otras figuras, por ejemplo, un mecánico o un empleado de fotocopias, y los informantes reconocían no tener interés en la calidad humana de esas otras figuras. 
Al presentárseles el ejemplo hipotético de un sacerdote que fuera excelente para dar sermones y consejos, pero que no poseyera las virtudes morales que los informantes esperaban de sus políticos, estos desaprobaron al sacerdote hipotético, señalando que de él sí esperaban virtudes morales y argumentando que la diferencia era que el sacerdote hacía llamados a la moral y la virtud, mismos que sólo aceptarían si quien los emite los sigue fielmente.

También se les pidió que trataran de explicar qué rasgos compartía el sacerdote con el político que no fueran compartidos por, por ejemplo, un mecánico o un empleado de fotocopias:

¿Por qué? ¿Qué tiene el común el padre con el gobernador y que no comparten con el de las copias?

-Bueno, porque si dice y dice cosas y hace lo contrario, entonces nadie le creería, porque si estás poniendo la confianza en alguien es porque le estás creyendo lo que te está diciendo, y si sabes que es mentira, no va a haber confianza, es, por ejemplo, como el presidente actual, nadie confía en él, nadie le cree, todos lo tienen en un concepto de burro, de tonto, o sea, aunque haga cosas bien o mal, independientemente de lo que haga, nadie lo baja de ese concepto.

$\mathrm{Al}$ igual que el término líder resaltado anteriormente, la idea de que el presidente actual tiene una mala imagen "independientemente de lo que haga" será recuperada en las conclusiones. De momento, es importante rescatar que la expectativa moral no es universal: los informantes están dispuestos a tolerar defectos morales en quienes les prestan ciertos servicios o proveen algunos bienes, pero los puestos públicos son especiales, esto es, tienen una carga moral que pocos oficios comparten.

Ahora bien, ningún entrevistado logró aclarar por qué exactamente hay una expectativa moral sobre el sacerdote y el político no existente hacia otros oficios. Algunos 
intentaron explicar la del sacerdote asegurando que los consejos o discursos del mismo serían menos efectivos si se supieran sus fallas, pero reconocían que el rol del político no se centraba en dar discursos, por lo que la incoherencia acciones-discurso no explicaría el caso del gobernante.

Todos los informantes dijeron desear funcionarios "humanos”, pero aún apoyados en los ejemplos sobre otros oficios, ninguno logró explicar por qué querían gobernadores con dicha característica.

Estas dificultades no se manifestaron cuando se pidió a los informantes señalar qué consideraban que hacía malo a un político: todos señalaban espontáneamente a la corrupción. Lo más importante aquí, sin embargo, es que ni las virtudes humanas ni la corrupción parecieron importar según su impacto en la eficiencia de la administración pública:

¿Te preocupa la corrupción en términos estrictamente financieros?

-No mucho.

¿Qué te preocupa entonces de la corrupción?

-Que no hagan las cosas que propusieron, que nada más justifiquen un gasto y no lo hagan.

Pero, ¿eso te preocupa porque crees que va a ser mal administrador? ¿O cómo?

-No, porque estamos teniendo un delincuente como líder, yo básicamente [sic], como persona, no es como, por decir, buena persona.

¿Considera usted que un político que sea corrupto, necesariamente va a ser mal administrador?

-No necesariamente, puede ser muy hábil financieramente o tener buenos asesores y hacer, ser muy corrupto discreto, digamos.

¿Por qué quieres un gobernador honesto?

-[...] Porque, pues, en sí sabemos que en este ambiente, ahora sí que como le había dicho, yo no sé mucho de política, yo lo que digo es 
porque lo he visto, lo he sentido y creo que independientemente de eso, ya merecemos alguien que sea un poco honesto, porque ahora sí que ninguno ha sido digamos que muy limpio, de los gobernadores que yo he conocido y han sido de Puebla, pero como usted dice, independientemente de eso a la [sic] mejor haga muchas obras.

-Porque, por ejemplo, hay cosas de política que implican directamente con las personas, y si no tienes empatía hacia las personas, este, ¿no? digamos que entra un conflicto, por ejemplo, si es una persona que no respeta [a] las personas mayores, a la mejor cuando llegue algún programa social de apoyo a los adultos mayores, va a ser el último caso que vaya a ver.

Pero, entonces, ¿no sigues pensando en una lógica de que sea buen administrador?

-También.

De los ejemplos transcritos, se debe subrayar que los informantes buscan la calidad moral y desprecian la corrupción por sí misma y no en función de cómo impacta el desempeño de los Gobiernos. El primer fragmento, por ejemplo, muestra un informante más preocupado por la mentira de justificar una obra que no se realizó que por la no-realización de la misma. En el penúltimo fragmento, el entrevistado parece pensar en voz alta y tratar infructuosamente de comprender por qué quiere honestidad en su Gobierno, aun cuando le queda muy claro que la desea: nótese cómo justifica su punto de vista más en su "sentir" que en algo racional. El último fragmento presenta un entrevistado que también está seguro de que quiere honestidad y valores morales, pero fracasa al tratar de explicar su demanda y termina hablando de la eficiencia gubernamental, que anteriormente ya había desligado de la cuestión moral.

Así, pues, los informantes demandaron virtudes morales de sus políticos con mucha fuerza y poca claridad, pero dicha solicitud parece finalmente poco vinculada al desempeño real del Gobierno. Para profundizar en este aspecto, se 
les pidió a los entrevistados que eligieran entre dos candidatos hipotéticos: uno carente de las virtudes morales, corrupto, pero que garantizara un excelente desempeño del Gobierno, y el otro poseedor de virtudes morales solicitadas, pero incompetente, lo que implicaría un pobre desempeño gubernamental de su parte. Las respuestas a este ejercicio dejan claro el gran peso de lo moral y también sugieren inicialmente la posibilidad de que la eficiencia de la administración pública sea más una justificación discursiva que un determinante de la evaluación del Gobierno:

Te voy a hacer una pregunta, si tú tuvieras que elegir entre un candidato que tú sabes que es mala persona, pero que es excelente administrador, y un candidato que es un administrador francamente malo, pero es buena persona, ¿por cuál optarías?

-El menos peor, bueno, pues, bueno, poniéndolo ya así estrictamente, te diría que el que es mejor administrador.

¿A cuál elegirías?

-(risas) Al absolutamente torpe, lo admito.

-Ay, no sé, pues, creo que por el que sí hace las cosas, aunque se lleve dinero.

-(silencio) Sí, lo estoy pensando, porque sí es alguien honesto, pero imagínese, si no hace nada, pues también, no, cómo sería el avance, no habría avance.

-Creo que desafortunadamente por el que sabe administrar.

-Mmm, ¿por cuál votaría?, lógicamente por el que se vaya nomás por eso, por lo que haga.

¿Entonces te irías por un eficiente aunque sea corrupto?

-Eficiente aunque sea corrupto, no, realmente no.

¿Preferirías un honesto aunque no sea muy bueno administrando?

-No, es que igual, si no es un buen administrador, pues lógicamente, va a sacarte igual. 
¿Entonces, cuál elegirías?

-Pues yo elegiría al otro, al que esté haciendo, el que va a hacer cosas y va a robar, igual, todos al final van a robar, ino?

-Mmm, yo sinceramente, a pesar de que me pesara, por el corrupto, pues sí porque cuando menos haría una gestión posiblemente a beneficio del pueblo que es lo que estamos buscando, ¿no?

-Yo creo que con [sic] el honesto.

-Pues no sé cuál, cuál daño dé más [sic], ¿no? Este, pues la ineficiencia puede quebrar el municipio, el estado, $y$ a lo mejor puede ser más dañino que el corrupto que hace bien las cosas, esa es la paradoja, por eso digo, en este momento estamos en esa situación.

Lo más evidente en los fragmentos de entrevista seleccionados es que las virtudes morales tienen un peso semejante a la eficiencia gubernamental, pues los informantes no respondieron clara y unívocamente, pero el hallazgo más valioso se encuentra en el estrés que provocó la pregunta. Es comprensible que una persona tarde y vacile al tomar una decisión si las opciones tienen un costo/ganancia semejante, pero eso no explica la incomodad que pareció generar la pregunta: casi todos los entrevistados dudaron mucho antes de emitir su respuesta, y algunos intentaron escapar del ejercicio. Por ejemplo, cuando se dijo que a fin de cuentas todos los candidatos serían corruptos, muchos de los que optaron por el corrupto eficaz lo hicieron con pesar y desagrado, y quienes prefirieron al honesto mostraban cierta vergüenza respecto a su decisión. La dificultad con que los informantes tomaban su decisión y las conclusiones estadísticas de la primera parte del trabajo apuntan a una hipótesis que podría cambiar la manera en que entendemos el descontento ciudadano hacia el Gobierno. Dicha hipótesis se señala en las conclusiones.

Hay que señalar que las impresiones sobre el desempeño gubernamental real fueron vagas. Como se dijo, la elección poblana del 2016 enfrentó a dos candidatos que ya habían 
sido presidentes municipales, por lo que entre los informantes abundaba la información sobre el desempeño pragmático de ambos contendientes. Pese a esto, ningún informante presentó ninguna cifra cuando habló de desempleo o seguridad: sólo se expresaban ideas generales y nunca estadísticas precisas o expectativas claras. Los entrevistados describían el desempeño de los candidatos en función de las construcciones que se habían realizado en el municipio o una vaga idea personal de la seguridad, por ejemplo, sin ningún dato concreto. Los informantes tampoco señalaron cuáles serían sus expectativas específicas en economía o seguridad ni presentaron diagnósticos básicos del estado o la ciudad.

Hay que señalar que hubo algunas excepciones a lo señalado, en concreto en tres de las entrevistas realizadas. Ante la pregunta ya descrita de corruptos eficaces vs. ineptos honestos, un entrevistado dijo no tener problemas con aceptar la corrupción, y justificó su postura señalando las virtudes de un antiguo presidente:

-Eso estaría muy bien, a mí me parecería muy bien, tendríamos el famoso diezmo, que es el $10 \%$ de las grandes cantidades, yo veo que con ese diezmo que se llevara, pero que dejara el $90 \%$ para desarrollo estatal, de infraestructura, de obra pública, sí estaría muy bien. Eso a mí no me molestaría, pero siempre en cuanto [sic] supiéramos qué se va a llevar [...] muchos de los grandes presidentes que tuvo este país, desde luego los antiguos, eran eso, había frases de don Alfonso Ruiz Cortines, por ejemplo, que decía que hay que hacerlo así, pero hay que "salpicar"; él quería decir con eso que todos tuviéramos trabajo, todos tuviéramos el estómago lleno, y la gente no sufría en esos periodos, el PRI era corrupto, el presidente también, pero teníamos chamba todos, esos fueron los grandes estadistas mexicanos, aquellos viejos políticos.

Este mismo informante, cuyas respuestas fueron similares en lo general a las de los otros informantes, aceptó la corrupción mientras esta implicara eficiencia gubernamental. Sólo 
otro caso reaccionó de forma semejante: un estudiante que mostró una postura particularmente egoísta. En todas las entrevistas se preguntaba si se prefería a los Gobiernos que favorecieran los intereses personales del informante o a las propuestas que busquen el bien general aun si no beneficiarían directamente al entrevistado, y todos los informantes dijeron preferir el bien común salvo dicho estudiante, que se dijo poco preocupado por la corrupción y dispuesto a aceptarla si implicaba un Gobierno eficaz.

\section{Conclusiones}

Como se mencionó al inicio del trabajo, el desencanto y, más específicamente, la desaprobación del Gobierno son un asunto de gran importancia y frecuentemente se asume que el mal desempeño del Gobierno es su causa principal. Del trabajo presentado, se pueden desprender tres conclusiones, cada una con su propio grado de certeza y precisión.

En primer lugar, la evaluación del Gobierno no depende tanto de su desempeño real como se suele pensar en los estudios sobre desencanto político en el México actual. El Latinobarómetro muestra que los ciudadanos con peores opiniones sobre economía y seguridad (claros indicadores del desempeño de un Estado) son quienes tienen peores evaluaciones del Gobierno. Igualmente, la mayoría de los entrevistados dice tomar en cuenta el desempeño de los funcionarios para emitir sus juicios.

Sin embargo, la confianza en el Gobierno y sus órganos parece muy estable en el tiempo, mientras que el estado objetivo de la economía y la seguridad fluctúa fuertemente sin relación aparente con aquella. Además, no parece haber relación entre la economía y seguridad de los estados y su evaluación del Gobierno. A pesar de que los entrevistados se decían interesados en el rendimiento de los Gobiernos, mucho de su juicio parecía determinado por una expectativa 
moral de sus funcionarios, la cual era más o menos independiente de la capacidad administrativa de los servidores públicos.

Este hallazgo es crucial porque sugiere que aun si el Gobierno mejorara, la ciudadanía no necesariamente lo vería mejor. Por ejemplo, debe recordarse al informante que hablaba de la permanencia de la mala imagen del presidente Enrique Peña Nieto, "aunque haga cosas bien o mal, independientemente de lo que haga". Es decir, mejorar al Gobierno de México bien puede ayudar a la población, pero no necesariamente mejorará la imagen del Gobierno o de los políticos.

Además, el Gobierno mexicano gasta mucho dinero en un esfuerzo de comunicación social que generalmente se concentra en mostrar logros pragmáticos de la administración pública, pero este aspecto no parecía tan relevante para los entrevistados. Probablemente si se profundiza la investigación sobre la demanda moral insatisfecha se podrían hacer sugerencias concretas para ajustar la comunicación social del Gobierno y mejorar así su imagen, ayudando de este modo a la consolidación democrática.

La primera conclusión de este trabajo, que el desempeño objetivo del Gobierno no determina mucho de su evaluación, contrario a lo que se suele pensar, supone un hallazgo relevante, pero es un tanto estéril pues en sí misma no genera nuevas guías teóricas que permitan comenzar a buscar mejores causas de aquello que este artículo aspira a explicar.

En cambio, la segunda conclusión del presente trabajo está sustentada en una muestra mucho menor que la primera, pero que sí aporta nuevas propuestas teóricas: una parte importante de la evaluación ciudadana del Gobierno no está relacionada con el desempeño real de los funcionarios, sino que responde a un deseo insatisfecho en la ciudadanía de tener servidores públicos que también sean líderes morales. 
Esta segunda conclusión hace reconocer a los investigadores que antes han dado peso al tema de la corrupción. Algunas investigaciones previas atribuyen la evaluación del Gobierno no sólo respecto de su desempeño, sino que mencionan también a la corrupción como un factor. Sin embargo, los entrevistados no sólo desean gobernantes no-corruptos, pues quieren que sus funcionarios sean ejemplos cívicos positivos (no sólo figuras neutrales). Así pues, la corrupción es sólo una fracción de esta aparente demanda moral, pero no hay que dejar de reconocer a quienes la subrayaron como un factor relevante y ajeno a la eficiencia del Gobierno.

Los informantes dijeron ver a sus gobernantes como lideres, deseaban ver a sus funcionarios como ejemplos de moralidad y civismo que los inspiren a ser mejores ciudadanos; hubo quienes decían que la sociedad se merece esas cualidades en sus figuras públicas. Infortunadamente, ningún informante se dijo satisfecho en este aspecto, pues no creían que los funcionarios públicos (eficientes o no) tuvieran la clase de valores que los convertirían en líderes sociales; esta demanda insatisfecha fue intensamente expresada en las entrevistas.

En el ámbito de la ciencia política en México, podría parecer extraño que un deseo de liderazgo cívico o moral determine tanto el juicio ciudadano, pues, después de todo, la ciencia política lleva bastante tiempo funcionado bajo una lógica de laicidad de las figuras públicas: generalmente, trabaja bajo el supuesto de que los funcionarios son sólo burócratas que -a lo más- representan ideologías de los votantes, y que no tienen valor en sí mismos, pero el poder político constantemente ha estado vinculado con una carga simbólica ajena a su rol administrativo. La historia europea, por ejemplo, contiene ejemplos de cuando el cuerpo del rey era mucho más que materia y se volvía un objeto casi sagrado (Kantorowicz, 1985). 
En casi todas las culturas, el ejercicio del poder está marcado por un halo de sacralidad. La lógica moderna y liberal, generalmente abrazada por la ciencia política actual, reduce a los gobernantes a meros funcionarios, pero la antropología, la historia y los datos aquí encontrados apuntan a una visión mucho más sacralizada de los gobernantes. Quizá, tomar distancia de las posturas liberales comunes en la ciencia política y acercarse más a la antropología ayude a comprender mejor el desencanto político que amenaza a la democracia mexicana.

Así, pues, la primera conclusión se sustenta en años de encuestas que involucraron a varios miles de mexicanos, mientras que la segunda es un hallazgo relativamente novedoso de un trabajo cualitativo localizado. Además, las entrevistas aquí presentadas dejan preguntas abiertas sobre la naturaleza precisa de esta demanda moral de los ciudadanos: no es claro si se trata de un tema de cultura política premoderna, o si de un asunto antropológico inherente a toda forma de Gobierno; ni siquiera queda claro si se trata de un tema de moral o de ética.

Así, si la primera conclusión parece más sólida que la segunda, esta última es mucho más fértil, pues mientras que la primera sólo muestra un error y la futilidad de continuar una línea de pensamiento, la segunda sugiere líneas de investigación futuras. Además, la robustez de esta segunda conclusión es un asunto relativo, pues marca claramente un rumbo. Por ejemplo, estos hallazgos cualitativos dejan claro que no tiene mucho sentido buscar algún indicador económico refinado que explique el desencanto político, así como tampoco parece prometedor analizar si el desempeño de otra área (cultura, salud, educación, etc.) explica la evaluación ciudadana.

Si bien de momento no es posible ahondar demasiado sobre la demanda moral, hay fuerte evidencia de que es en esta área donde se podrían encontrar las mejores variables 
que explicarían el desencanto político. Ahora que sabemos que la evaluación ciudadana no depende mucho de características objetivas del Gobierno, sino de un tema moral, será necesario aclarar mucho más esta demanda insatisfecha y conocer con mucho mayor detalle sus características, causas y consecuencias, lo que bien podría ocupar varias investigaciones futuras.

Finalmente, los datos aquí presentados apuntan a una tercera conclusión. De concretarse, nos permitiría explicar no sólo la desaprobación del Gobierno, sino también la existencia de la hipótesis inicial relacionada al desempeño del Estado. La información aquí presentada podría sugerir una inversión de causalidades: al inicio del trabajo, se mostró que quienes tienen una mala opinión sobre seguridad y economía también evalúan mal al Gobierno, y esta correlación podría ser considerada como evidencia de que la gente evalúa mal al Gobierno porque este ha fracasado en economía y seguridad, sin embargo, una correlación matemática no determina el sentido de la causalidad con la que está ligada, así que la misma correlación serviría también para probar que cuando la gente se molesta con el Gobierno tiende a evaluar mal la economía y la seguridad, y lo más interesante es que esta segunda posibilidad concuerda más con los datos aquí mostrados.

Si el desempeño determinara la evaluación del Gobierno, se esperaría que los indicadores objetivos se relacionaran con la evaluación, cosa que no sucede. Sin embargo, si por razones más bien morales las personas evaluaran al Gobierno y justificaran su evaluación con argumentos sobre desempeño, entonces no tendría por qué haber una relación entre la eficiencia objetiva del Gobierno y su evaluación, pero sí entre la eficiencia percibida y el juicio al Gobierno, y fue justo así como se comportaron los datos.

Además, hay que recordar que los informantes del Latinobarómetro no mostraron muchas capacidades para 
evaluar la economía ni la seguridad, necesarias para que el desempeño objetivo del Gobierno sea causa efectiva de su evaluación. Por otro lado, si la opinión sobre economía y seguridad es más una justificación que una razón real, no es necesario estar bien informado al respecto: vagas impresiones bastan, y justo así fueron las impresiones encontradas en las entrevistas.

Finalmente, hay que recordar cuando se pidió a los entrevistados que eligieran entre un candidato con eficiencia y otro con moral. Si el desempeño del Estado fuera causa efectiva del juicio del Gobierno, y además fuera independiente de la expectativa moral, se entendería que las personas tardaran en decidir ante opciones de beneficio semejante, pero no se esperaría incomodidad ni estrés en el ejercicio. Por otro lado, si el desempeño gubernamental es una mera justificación de un juicio moral previo, sí se entiende la incomodidad de la pregunta, pues las personas que optaran por el corrupto eficaz lo estarían haciendo siguiendo la lógica de su justificación, pero sin estar emocionalmente convencidas, mientras que las que elijan honestidad serían fieles con su sentir, pero se sabrían descubiertas al traicionar el argumento lógico con el que justificaban su demanda moral.

Si los entrevistados pudieran dar cuenta y justificar su demanda moral, no necesitarían una justificación y simplemente expondrían su argumento, sin embargo, las personas mostraron serias dificultades para justificar o explicar su demanda moral, por lo que es posible que se busque una justificación a esa demanda compleja de exponer. Justo esto se vio en algunos informantes que intentaron explicar su demanda moral vinculándola con el desempeño del Gobierno, sólo para terminar reconociendo que ser un ciudadano modelo no implica ser un buen administrador ni viceversa. A esto hay que agregar la declaración de un informante que directamente reconoció que el presidente tiene mala imagen "independientemente de lo que haga", 
frase que coincide con la hipótesis de que el desempeño se utiliza para justificar el juicio del Gobierno y no con la idea de que es este desempeño el que determina el juicio.

Los datos aquí presentados apoyan la hipótesis del desempeño gubernamental como justificación más que como causa efectiva de la mala imagen del Gobierno, misma que parece más vinculada a una demanda moral insatisfecha. Sin embargo, esta propuesta se quedará como una hipótesis. La metodología del Latinobarómetro no está directamente pensada para poner a prueba esta idea y, por otro lado, la técnica cualitativa es altamente inductiva, por lo que no hay una prueba adecuada en un sentido refutacionista.

Para asegurar que la eficacia gubernamental es más justificación que causa de la desaprobación del Gobierno, será necesario profundizar estas investigaciones más adelante y realizar un estudio ex profeso que busque la relación entre la expectativa moral insatisfecha, el desempeño del Gobierno y la evaluación ciudadana. Como se puede ver, esta tercera conclusión queda como una mera hipótesis, y debe tomarse como una conjetura hasta tener mayor información.

Así pues, este trabajo muestra que la insatisfacción con el Gobierno está poco determinada por el desempeño objetivo de este, y, en lugar de eso, parece explicarse por una demanda moral que los ciudadanos ponen sobre sus gobernantes. Quedan por investigar las características precisas de esta demanda, así como la posibilidad de que sea esta la causa real de los juicios, y el desempeño una mera justificación discursiva.

Bibliografía

\section{6}

Alonso, J. (1994). “Partidos y cultura política”, en J.Alonso (Ed.), Cultura política y educación cívica (pp. II5-184). México: CIIHUNAM.

Alonso, J. (20I0). "El movimiento anulista en 2009 y la abstención”. Espiral estudios sobre Estado y sociedad, I6(47), 
9-46. Recuperado de: http://espiral.cucsh.udg.mx/index. PhP/EEES/article/view/ / 452/I 282

Arend, L. (1999). Patterns of Democracy. New Haven: Yale University Press.

Assies,W., Calderón, M.A., y Salman, T. (2002). "Ciudadanía, cultura política y reforma del Estado en América Latina”. América Latina hoy, 32,55-90. Recuperado de: http://revistas.usal.es/index.php/ I I30-2887/article/view/2389/2439

Banco Mundial (2017). Recuperado de: https://datos.bancomundial.org/indicador/SL.UEM.TOTL.Zs?locations=MX

Córdova, A., y Seligson, M. (20I0). "La gobernabilidad y el apoyo a la democracia estable en Latinoamérica: resultados del Barómetro de las Américas 2008”. Journal of Democracy en español, 2, 28-46. Recuperado de: https:// www.vanderbilt.edu/lapop/insights/ITB030es.pdf

Consejo Nacional de Evaluación de la Política de Desarrollo Social (20I5a). Recuperado de: http://www.coneval.org. $\mathrm{mx} /$ SalaPrensa/Documents/Comunicado005_Medicion_pobreza_20I4.pdf

Consejo Nacional de Evaluación de la Política de Desarrollo Social (20I5b). Recuperado de: https://www.coneval.org. $\mathrm{mx} /$ Medicion/EDP/Paginas/Evolucion-de-las-dimensiones-de-la-pobreza-1990-20|4-.aspx

Cuna, E. (2006). "Reflexiones sobre el desencanto democrático. El caso de los partidos políticos y los jóvenes en la Ciudad de México". Sociológica, 2 I (6I), 95-I34. Recuperado de: http://www.sociologicamexico.azc.uam. mx/index.php/Sociologica/article/view/259/237

Cuna, E. (20I2).“Apoyo a la democracia en jóvenes estudiantes de la Ciudad de México. Estudio sobre el desencanto ciudadano juvenil con las instituciones de la democracia mexicana”. Polis, 8(2), I07-I5I. Recuperado de: http:// polismexico.izt.uam.mx/index.php/rp/article/view/83/76 García, J. (2004). El malestar de la democracia en México. México: Plaza y Valdez. 
Bibliografía

Gil de Zúñiga, H., Jung, N., y Valenzuela, S. (20I2). "Social Media Use for News and Individuals' Social Capital, Civic Engagement and Political Participation”. Journal of Computer Mediated Communication, I7(3), 319-336. Recuperado de: https://academic.oup.com/jcmc/article/I7/3/319/4067682

Gómez, S. (2009). ¿Cuántos votos necesita la democracia? México: Instituto Federal Electoral.

Gutiérrez, H. (20l7). "Buenos ciudadanos que no votan. Mecanismos entre desencanto y abstención”. Sociológica, 32(92), |4|-|73. Recuperado de: http://www.sociologicamexico.azc.uam.mx/index.php/Sociologica/article/ view/ I |42// 2 | |

Hurtado, L.A. (20|4). “¿Encuestas o propaganda? La estrategia política, elecciones 2012”. Razón y palabra, /8(87). Recuperado de: http://www.razonypalabra.org.mx/N/ N87/V87/I0_Hurtado_V87.pdf

Instituto Nacional de Estadística y Geografía (20l6). Recuperado de: http://www.beta.inegi.org.mx/temas/ victimizacion/

Kantorowicz, E. H. (1985). Los dos cuerpos del rey. Madrid: Alianza.

Krotz, E. (1990).“Antropología, elecciones y cultura política”. Nueva antropología, I I (38), 9-19. Recuperado de: https:// revistas colaboracion.juridicas.unam.mx/index.php/ nueva-antropologia/article/view/I5565//3896

Krotz, E. (1996). El estudio de la cultura política en México. México: CIESAS.

Latinobarómetro (20 I5). Recuperado de: http://www.latinobarometro.org/latContents.jsp

López Sánchez, R. (20I3). “El abstencionismo como fenómeno político en la sociedad contemporánea”. Culturales, I(I), 53-68. Recuperado de: http://culturales.uabc. $\mathrm{mx} /$ index.php/Culturales/article/view/ /48//47 
Lutz, B. (2005a). "La participación electoral inconclusa: abstencionismo y votación nula en México”. Revista mexicana de sociología, 67(4), 193-826. Recuperado de: http://www.revistas.unam.mx/index.php/rms/article/ view/6039/5560

Lutz, B. (2005b). "El palimpsesto del abstencionismo electoral en México o la democracia a prueba". Espacios públicos, 8(I5), 5I-76. Recuperado de: http://ri.uaemex. $\mathrm{mx} /$ handle/20.500.I I 799/39782

Magallón, M. (1993). El apoyo a la democracia en América Latina. ¿Hacia un nuevo régimen internacional? México: UNAM.

Merton, R. K., y Kendall, P. (1946). "The Focused Interview”. American Journal of Sociology, 5 I (6), 54I-547. Recuperado de: http://www.journals.uchicago.edu/doi/ pdfplus/10.1086/219886

Meixueiro, M. (2009). "La representación política en México: una revisión conceptual y de opinión pública”. Revista legislativa de estudios sociales y de opinión pública, 2(3), 35-65. Recuperado de: http://www3.diputados.gob.mx/00I_diputados/006_centros_de_estudio/04_centro_de_estudios_sociales_y_de_opinion_publica/003_accesos_directos/002_publicaciones/003_revista_legislativa

Mijares, F. R. (2006).“Desafección política; principales causas del abstencionismo electoral en México”. Apuntes electorales, 5(23), 9-70. Recuperado de: http://aelectorales. ieem.org.mx/index.php/ae/article/view/602/580

Miller, W. E. (1980). "Disinterest, Disaffection, and Participation in Presidential Politics". Political Behavior, 2(I), 7-32. Recuperado de: https://link.springer.com/article/I 0.1007/BF00989754

Molina y Vedia, S. (2004). "Comunicación gubernamental, ¿encanto o desencanto?". Revista mexicana de ciencias políticas, 46(190), 31-45. Recuperado de: http:// 
Bibliografía www.revistas.unam.mx/index.php/rmcpys/article/ view/42432/38545

Mora, J., y Rodríguez, R. (2003). "Las elecciones intermedias del 2003: entre el desencanto político y la crisis de representación". El Cotidiano, 19(I22), 55-65. Recuperado de: http://www.elcotidianoenlinea.com.mx/pdf/ I2207.pdf

Offe, C. (2006). "Political disaffection as an outcome of institutional practices? Some post-Tocquevillean speculations", en M. Torcal, y J. R. Montero (Eds.), Political Disaffection in Contemporary Democracies: Social Capital, Institutions and Politics (Pp. 23-45). Londres: Rutledge.

Pinkleton, B., Austin, E., Zhou, Y., Willoughby, J., y Reiser, M. (20I2). "Perceptions of News Media, External Efficacy, and Public Affairs Apathy in Political Decision Making and Disaffection". Journalism \& Mass Communication Quarterly, 89(I), 23-39. Recuperado de: http://journals. sagepub.com/doi/full/I0.I I 77/I0776990 I I 428586

Prud'homme,J.F.(2015).“'La insatisfacción con la democracia en el México actual”. Foro internacional, 55(I), 302-345. Recuperado de: http://forointernacional.colmex.mx/ index.php/fi/article/view/2268/2258

Sánchez, L. F., y Aceves, F. J. (2008). “Campañas políticas y configuración del voto electoral en 2006. Encuestas electorales y publicidad política". Revista mexicana de ciencias políticas y sociales, 50(202), 93-I I 6. Recuperado de: http://www.revistas.unam.mx/index.php/rmcpys/ article/view/42602

Sarsfield, R. (2004). “¿Democracia a pesar de todo? Evaluación del pasado económico, expectativas futuras y preferencia por un Gobierno democrático en Argentina". Perfiles latinoamericanos, 24, 169-202. Recuperado de: http://perfilesla.flacso.edu.mx/index.php/perfilesla/ article/view/262/216

Schedler, A., y Sarsfield, R. (2009). “Demócratas iliberales. Configuraciones contradictorias de apoyo a la demo- 
cracia en México". Espiral estudios sobre Estado y sociedad, 15(44), I23-159. Recuperado de: http://espiral.cucsh.udg. mx/index.php/EEES/article/view/ / 387/ I 25 I

Schyns, P., y Koop, C. (2010). "Political Distrust and Social Capital in Europe and the USA". Social Indicators Research, 96(I), 96- |45. doi: |0. I007/s | | 205-009-947|-4

Schmitt-Beck, R., y Mackenrodt, C. (2010)."Social networks and mass media as mobilizers and demobilizers:A study of turnout at a German local election”. Electoral Studies, 29(3), 392-404. Recuperado de: https://www.sciencedirect.com/science/article/pii/S026 I 379410000235

Street, J. (20I I). Mass Media, Politics and Democracy. Nueva York: Palgrave MacMillan.

Sun, I., Hu, R., yWu,Y. (20I2). “Social Capital, Political Participation, and Trust in the Police in urban China". Australian \& New Zealand Journal of Criminology, 45( I), 87- I05. doi: I0.1 I77/00048658 I I43 I329

Torcal, M. (2003). "Political Disaffection and Democratization History in New Democracies", en M. Torcal, y J. R. Montero (Eds.), Political Disaffection in Contemporary Democracies: Social Capital, Institutions and Politics (Pp. I57- 189). Londres: Rutledge.

Valencia, A., Peláez, E., Rúa, C., y Awad, G. (2010). “Abstencionismo; ¿por qué no votan los jóvenes universitarios?”. Revista virtual Universidad Católica del Norte, 3 I , 363-387. Recuperado de: http://revistavirtual.ucn.edu.co/index. $\mathrm{php} /$ RevistaUCN/article/view/49/107

Zemelman, H. (1990). Cultura y política en América Latina. México: Siglo XXI.

Zovatto, D. (2002). "Valores, percepciones y actitudes hacia la democracia. Una visión comparada latinoamericana: 19962002". América Latina hoy, 32, 29-53. Recuperado de: http:// revistas.usal.es/index.php/I I 30-2887/article/view/2387/2435 